\title{
THREE NEW FLEAS FROM SULAWESI, INDONESIA (Siphonaptera: Pygiopsyllidae \& Ceratophyllidae)
}

\author{
DURDEN L.A.* \& BEAUCOURNU J.C.**
}

\section{Summary:}

Gryphopsylla maxomydis n. sp. (Pygiopsyllidae), Medwayella rubrisciurae n. sp. (Pygiopsyllidae) and Macrostylophora theresae n. sp. (Ceratophyllidae) are described from endemic rodents in Sulawesi. Gryphopsylla maxomydis was collected from the murids Maxomys musschenbroekii and Paruromys dominator in Central Sulawesi (Sulawesi Tengah). However, M. musschenbroekii appears to be the true host of this flea because it has spiny pelage and $G$. maxomydis shows morphological adaptations for parasitizing spiny hosts including a remarkable "beak-like" structure on the head. This adatation is similar to a beak-like structure on the head of Gryphopsylla hopkinsi (Traub) which parasitizes the spiny murid Maxomys whiteheadi in Borneo (Sabah). Medwayella rubrisciurae was collected from the large tree squirrel Rubrisciurus rubriventer in Central Sulawesi and this represents the first report of this flea genus in Sulawesi. Macrostylophora theresae was recorded from the murids Bunomys fratrorum, P. dominator and Rattus xanthurus in North Sulawesi (Sulawesi Utara); most other members of this flea genus parasitize squirrels in the Oriental and Palaearctic zoogeographical regions.

KEY WORDS : Gryphopsylla maxomydis n. sp., Medwayella rubrisciurae n. sp., Macrostylophora theresae n. sp., flea, Siphonaptera, Pygiopsyllidae, Ceratophyllidae, Sulawesi, Indonesia.

T The indigenous flea fauna of Sulawesi, Indonesia is incompletely known (Durden \& Traub, 1990) but recent taxonomic papers have added to our knowledge of the presumably endemic fleas parasitizing endemic rodents on this unique tropical island. Recent papers on new fleas from Sulawesi have addressed members of the ctenophthalmid genus Neopsylla by Beaucournu \& Durden (1999), the leptopsyllid genus Sigmactenus by Durden \& Beaucournu (2000), and of the pygiopsyllid genera Stivalius by Beaucournu \& Durden (2001), Gymnomeropsylla by Durden

\footnotetext{
* Department of Biology, Georgia Southern University, Statesboro, Georgia 30460-8042, USA, and Institute of Arthropodology \& Parasitology, Georgia Southern University, Statesboro, Georgia 30460-8056, USA.

*** Laboratoire de Parasitologie et Zoologie appliquée, Faculté de Médecine, 2, avenue du Prof. Léon-Bernard, 35043 Rennes cedex, France, et Institut de Parasitologie de l'Ouest, même adresse.

Correspondence : Pr Jean-Claude Beaucournu.

E-mail : jbeaucou@univ-rennes1.fr
}

Résumé : Trois puces NOUvelles du Sulawesi, INDONÉSIE (Siphonaptera : Pygiopsyluidae et Ceratophyllidae)

Gryphopsylla maxomydis n. sp. (Pygiopsyllidae), Medwayella rubrisciurae n. sp. (Pygiopsyllidae) et Macrosylophora theresae n. sp. (Ceratophyllidae) sont décrites de rongeurs endémiques du Sulawesi. G. maxomydis fut collectée chez les rongeurs muridés Maxomys musschenbroekii et Paruromys dominator dans le Sulawesi Central (Sulawesi Tengah). Cependant, M. musschenbroekii apparaît comme le véritable hôte de cette puce, car il a un pelage épineux et, de son côté, G. maxomydis montre des adaptations morphologiques à un parasitisme de tels hôtes, en l'occurrence la remarquable structure de la tête en forme de "bec". Cette adaptation est semblable à la structure en "bec" de Gryphopsylla hopkinsi (Traub) qui parasite le rat épineux Maxomys whiteheadi à Bornéo (Sabah). Medwayella rubrisciurae fut capturée sur le très gros écureuil arboricole Rubrisciurus rubriventer, dans le Sulawesi Central, et représente le premier signalement de ce genre de puce au Sulawesi. Macrostylophora theresae n. sp. fut capturée sur les muridés Bunomys fratrorum, P. dominator et Rattus xanthurus dans le Nord Sulawesi (Sulawesi Utara); la plupart des autres puces de ce genre parasitent les écureuils dans les régions zoogéographiques Orientale et Palaearctique.

MOTS CLÉS : Gryphopsylla maxomydis n. sp., Medwayella rubrisciurae n. sp., Macrostylophora theresae n. sp., puce, Siphonaptera, Pygiopsyllidae, Ceratophyllidae, Sulawesi, Indonésie.

\& Beaucournu (2002), and Farhangia and Nestivalius by Mardon \& Durden (2003). Of these taxa, Gymnomeropsylla was described as a new genus.

Sulawesi is part of Wallacea, the zoogeographical transition zone between the truly Oriental fauna to the west and the truly Australasian fauna to the east. As such, many faunal elements on Sulawesi are represented by some taxa with Oriental affinities and other taxa with Australasian affinities. The indigenous flea fauna of Sulawesi rodents also shows this dichotomy, with the ctenophthalmid and leptopsyllid fleas originating from the Oriental region and the pygiopsyllid fleas originating from the Australasian region (Durden \& Traub, 1990). However, the number of pygiopsyllid taxa that parasitize indigenous Sulawesi rodents clearly outnumbers the number of ctenophthalmid and leptopsyllid taxa that parasitize them and, in this paper, we describe two additional species of pygiopsyllids from endemic Sulawesi rodents. In addition, we describe a 
new species of Macrostylophora, a representative of the family Ceratophyllidae, which, like Sulawesian members of the families Ctenophthalmidae and Leptopsyllidae, has Oriental affinities.

\section{RESULTS}

\section{GRYPHOPSYLLA MAXOMYDIS N. SP}

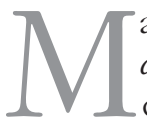
aterial examined: holotype male ex Paruromys dominator (Thomas, 1921) (Rodentia, Muridae), Indonesia, Sulawesi Tengah (Central Sulawesi), Gunung Kanino ( $\left.1^{\circ} 17^{\prime} \mathrm{S}, 120^{\circ} 08^{\prime} \mathrm{E}\right), 4,800 \mathrm{ft}$. (1,463 m), 2 February 1975, G.G. Musser rec. (AMNH 225392; ASE 2484; Robert Traub collection no 894806; inscription "photo" marked in pencil on slide; paratype male ex Maxomys musschenbroekii (Jentink, 1878) (Rodentia, Muridae), Indonesia, Central Sulawesi, Lake Lindu (= Danau Lindu), Tomado ( $1^{\circ} 19^{\prime} \mathrm{S}, 120^{\circ} 03^{\prime} \mathrm{E}$ ), 1,000 m, 14 August 1973, G.G. Musser rec. (AMNH 223245; ASE 467; Robert Traub coll. n 894740) (sternite VIII dissected and mounted separately on the same slide).

Etymology: specific epithet derived from Maxomys, the true primary host genus ( $c f$. Discussion).

Deposition of Types: Carnegie Museum of Natural History (CMNH), Pittsburgh, Pennsylvania, USA (Robert Traub Collection of Siphonaptera).

\section{DESCRIPTION}

Head (Fig. 1) immediately characterized by a "beak", similar to that of Gryphopsylla hopkinsi (Traub, 1957): the anterior part is slender, tapering, and projected forward. This protuberance is, however, different from that of G. hopkinsi, in that it is broader and has a small accessory projection at the base of the resulting sinus and that this sinus is clearly more open in G. maxomydis. The ventral contour of the gena is, in our two examples, not discernable because it is overcleared, the margin being very fine near the stipe which we have figured for this reason. Labial palp with four segments, extending $3 / 4$ of the length of coxa I. Eye discretely lobed but not reniform. The rows of frontal bristles are irregular; $1^{\text {st }}$ row with five (or six) bristles; the interpretation of the other rows (five rows?) seems impossible. In total, including the $1^{\text {st }}$ row, we note 18 medium or long bristles. Three rows of occipital bristles. The occipital groove is clear but not deep. The basal section of the antennal fossa is finely striated. Thorax. Prothorax (Fig. 1): an anterior row of four shorter bristles and a distal row of five bristles present; ctenidium with a total of 24 spines. Mesothorax with a pair of pseudo-setae (one on each side), so close to the collar that they could be confused with a thickening of this structure. Four rows of bristles of increa- sing size from anterior to posterior, the last, composed of nine longer bristles, although the rows are irregular. Metathorax: three rows of bristles, the last having six; metepimeron with nine bristles; the spiracle is larger than those of the abdomen, and is in the shape of a pine nut. Pleural arch present.

Tibiae I-III, each with seven notches and with robust bristles. The $3^{\text {rd }}$ pair of bristles on the three terminal tarsi I-III is displaced towards the interior. four spiniform bristles on the distal portion of tarsi I and II; bristles on the posterior margin of tibia III are well developed and in the form of "false-ctenidia". $1^{\text {st }}$ and $2^{\text {nd }}$ tarsal segments of claw III, long, the first practically as long as the tibia.

Abdomen (unmodified segments). Three ctenidia on tergites II-IV, with, respectively 15, 13 and 11 spines, in total. Seven long bristles on tergites II-VII; spiracle small and acuminate, situated mid-way between bristles 6 and 7. Two ante-sensilial bristles on tergite VII, the most dorsal less than half the length and width of the following one; these bristles are recessed (submarginal) and borne along the border of the segment, one equal in length and width as the inferior bristle; there is an extension of the tergite between the ante-sensilial bristles to the right and left; there are no small lobes bordering these bristles, dorsally or ventrally, in the strict sense of the term. Sternite II with 3-4 small bristles, all marginal, and one slightly longer and distal. Sternite III with 3-5 small bristles in two "patches" and two robust bristles; sternite IV with 3-6 small, then 2-3 long bristles; sternite $\mathrm{V}$ with 3-4 small, then three long bristles; sternite VI with four small, then three long bristles; sternite VII with 4-5 small, then three long bristles.

Abdomen (modified segments). Segment VIII (Fig. 4): tergite small, as it frequently is in this genus and related genera; sternite well developed, smoothly convex except on its ventral margin, which is rectilinear. In the holotype, a tiny concavity is present on this border; this concavity is insignificant when compared to the distinct indentation visible in G. hopkinsi; this segment has been dissected and damaged in our paratype and can not be used in this perspective. This sternite has 20-22 bristles of variable size. Segment IX (Fig. 2): manubrium of tergite very wide basally, this width being nearly equal to half its length. Basimere with two portions as is characteristic of the Stivaliinae (sensu Smit, 1987): processus basimeris dorsalis triangular and lightly sclerotized; processus basimeris ventralis, large, strongly convex, with two bristles of which the ventral is the longer. Processus telomeris (or telomere, or "digitoid"), with sub-parallel margins, much wider at its base; up to the stiva it is rectangular, and not gently arched as in G. hopkinsi. The setation of this process is remarkably poor: two small marginal dorsal bristles (only one in the paratype); three short thick bristles at the angle 
of the stiva, as is typical for species of this sub-family; they appear to be missing in G. hopkinsi, in the initial drawing of Traub (1957, Figs 34), but, with reduced thickness, they are visible in the photograph of Traub (1980, Figs 37) and in the drawing of Mardon (1981, Fig. 623); some micro-bristles at the apex of the stiva, and one small area of the same type of bristles on the internal surface of the arm of the telomere and, of course, the large slightly curved bristles (4-5 of them) inserted in the inferior curvature uniting the arm and the stiva. Sternite: apex of proximal arm wide and pigmented on its dorsal margin. The distal arm is characterized, apically, by a small dorsal translucent lobe situated in front of the oblique, external setiferous line, the terminal part is convex with five spinform pigmented bristles, of increasing size and length towards the base, then three classic, but pigmented, bristles.

Phallosome (Fig. 3): median dorsal lobe (M.D.L., $c f$. Traub,1972; all other abbreviations cited hereafter are from the same source) arched and rectilinear as in G. hopkinsi. Hood (HD), large and convex (it is narrow and rectilinear in $G$. hopkinsi), but the postero-ventral section is over-cleared and not visible. "Alpha-portion" curved and acuminate. Phylax not discernable basally ; crochet process (CRP), long, fine and curved towards the exterior. Tubus interior (T.I.) long, rectilinear, and with an apex (S.I.T. or sclerotized inner tube) curved apically an with a basal "indented" portion.

Female unknown.

Dimensions (slide-mounted specimens): holotype: $2,7 \mathrm{~mm}$, paratype: $2,5 \mathrm{~mm}$.

\section{DisCUSSION}

The profile of the head in this new species, shows a "beak", immediately evocative of Stivalius (Gryphopsylla) hopkinsi Traub, 1957, from northern Borneo (Sabah). The status of this taxon has been modified several times, initially being treated as Migrastivalius (Gryphopsylla) hopkinsi in Traub 1980, then as Gryphopsylla hopkinsi (Traub, 1957), in Mardon (1978, 1981). Without hesitation, this new species is placed in this genus in the key of Mardon (1981). The genus Lentistivalius Traub, 1972, is not directly related.

Traub (1980, p. 21) wrote in his proposal of Gryphopsylla as a sub-genus (of Migrastivalius): "The major hosts are spiny rats and I suspect that the remarkable notch on the head of this flea serves as a device for gripping the stiff flat bristles characteristic of these rats. Dr. K. Jordan suggested (in litt.), prior to my describing (Gryphopsylla) in 1957, that I place it in a separate genus, but it seemed advisable to be rather conservative until more became known about the related taxa. For the time being, at least until we learn whether the snout is adaptative in nature, I prefer to regard Gryphopsylla as a subgenus. If the snout is indeed functional for gripping bristly or other hairs, then new species of unrelated fleas, modified in this manner, may be found infesting hosts with similar chaetotaxy or scansorial habits...".

We have chosen Maxomys musschenbroekii as the type host of $G$. maxomydis, precisely because it is a rodent with "spiny" fur. Nevertheless, Gryphopsylla hetera Lewis \& Jones, 1985, was described from a single male from South Sulawesi (Sulawesi Selatan), from this same wide-ranging Sulawesi-endemic murid rodent host (Musser, 1987), and this flea has a classical head contour that lacks any sign of a "beak". Paruromys dominator, the only other known host of G. maxomydis, has "normal" (non-spiny) pelage and is an oppotunistic rodent that utilizes diverse biotopes and apparently often occupies nests or burrows of various vertebrates. We have also recorded the ceratophyllid flea Dasypsyllus gallinulae klossi (Rothschild, 1919) from P. dominator (18 specimens from a total of 13 rats) in Sulawesi; however, this is a bird flea, essentially a parasite of passeriforms; $P$. dominator is therefore, very likely, an accidental host of G. maxomydis. Other murid rodents harboring members of the genus Gryphopsylla (sensu Mardon, 1981) are Maxomys whiteheadi (Thomas, 1894) (the type host of G. hopkinsi on Borneo), Maxomys bartelsi (Jentink, 1910) [host of G. jacobsoni (Jordan \& Rothschild, 1922) on Java], Leopoldamys sabanus (Thomas, 1887) (type host of G. jacobsoni on Sumatra) and Rattus rattus (L., 1758) (recorded host of G. jacobsoni on Borneo). Of these murid hosts, only M. whiteheadi has spiny pelage like M. musschenbroekii (Musser, 1979) and this corresponds to the postulated function of the cephalic "beak" of its Gryphopsylla flea and of the new species described herein. Gryphopsylla mjoebergi (Jordan, 1926), the only other flea currently assigned to this genus (sensu Mardon, 1981) has been collected from tree shrews (Tupaia montana Thomas, 1892) and a callosciurine tree squirrel [Callosciurus nigrovittatus (Horsfield, 1823)] in Borneo, and has a regularly shaped head. The two murid-associated species of Gryphopsylla with a cephalic "beak" are known from two separate but geographically adjacent islands, Borneo and Sulawesi; again, it would be premature to place them in the sub-genus "Gryphopsylla s. str.". Also, the convergence in the morphology between these two fleas, although somewhat different, fits within the framework of this genus (with respect to the phallosome, in particular), supporting the opinion of Traub with respect to the influence of the type of host fur, by the selection pressure that this can exert on ectoparasites. Smit $(1972,1987)$ has described some other morphological adaptations of fleas and we have, on various occasions (e.g., Beaucournu \& Gallardo,1977), confirmed these hypotheses. Under these circumstances, Gryphopsylla hopkinsi and G. maxomydis represent highly adapted forms but we are unsure whether their morphology is indicative of a more primitive condition. 

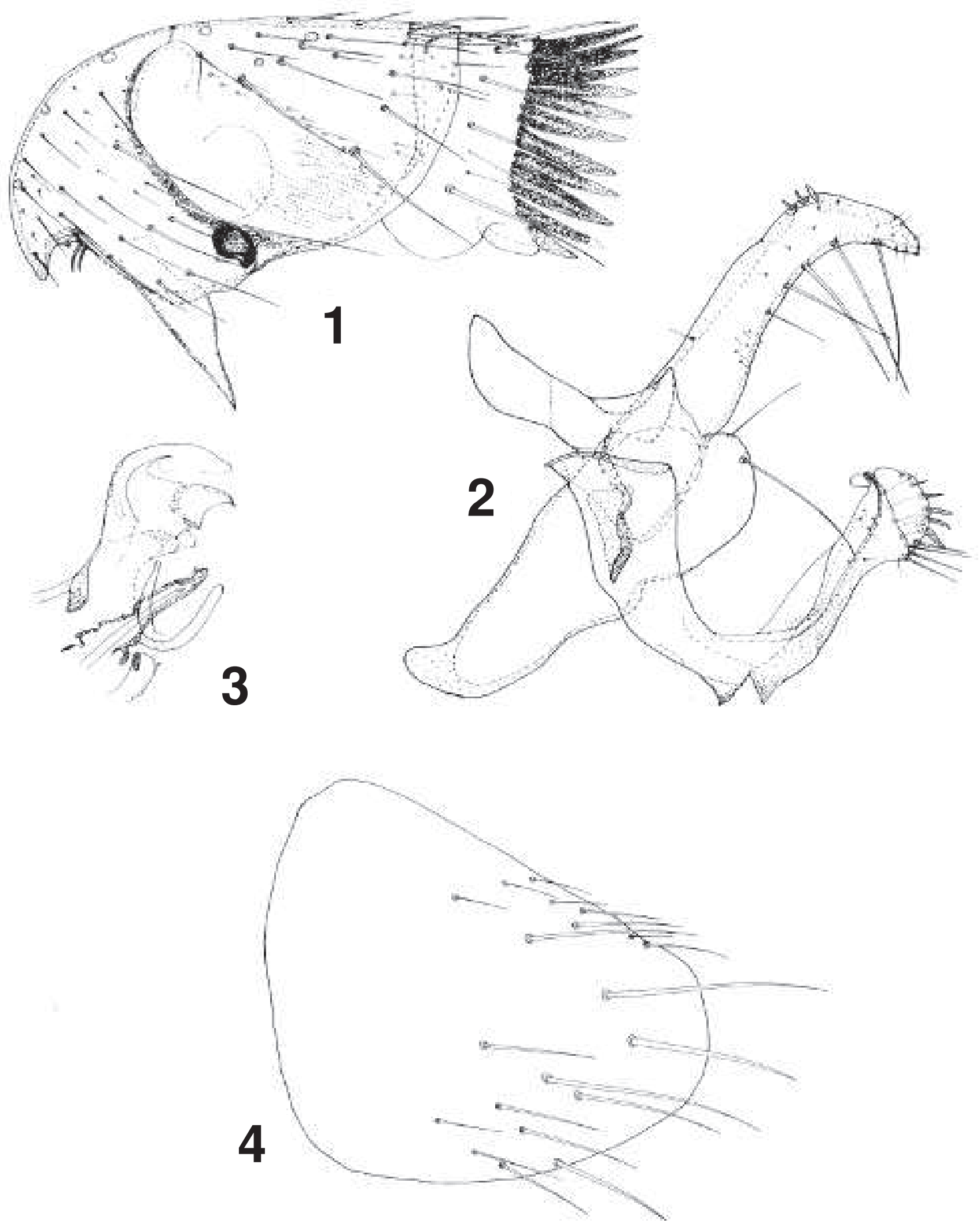

Figs 1-4. - Gryphopsylla maxomydis n. sp. Holotype. - 1: head and prothorax; 2: abdominal segment IX; 3: apex of phallosome; 4: tergite VIII. 
One can, perhaps in terms of analogy, consider these frontal structures as true anchoring devices, as in the very large spiniform preocular bristles, that are modified as hooks (ancistron!), in Ancistropsylla spp. fleas that parasitize small cervids, and that serve to attach to the host nasal region.

\section{MEDWAYELLA RUBRISCIURAE N. SP.}

Specimens examined: holotype male ex Rubrisciurus rubriventer (Müller \& Schlegel, 1844), (Rodentia, Sciuridae), Indonesia, Sulawesi Tengah (Central Sulawesi), Danau Lindu, Tomado (1 $1^{\circ} 19^{\prime} \mathrm{S}, 120^{\circ} 03^{\prime} \mathrm{E}$ ), 1,000 m, 25 August 1973, Dr. S. Kadarsan rec. (MZ 834; Robert Traub coll. nº B 98855; Bogor Museum/Museum Zoologicum Bogoriense) (sternite VIII and processus telomeris dissected and mounted separately on the same slide); allotype female ex female $R$. rubriventer, Indonesia, Central Sulawesi, Sungai Sadaunta $\left(1^{\circ} 23^{\prime} \mathrm{S}, 119^{\circ}\right.$ $58^{\prime}$ E), 2,500 feet $(762 \mathrm{~m}), 20$ September 1974, G.G. Musser rec. (AMNH 224624; ASE 1995; Robert Traub coll. $\mathrm{n}^{\circ} \mathrm{B}$ 94872); paratype male ex $R$. rubriventer, Indonesia, Central Sulawesi, Lake Lundu Tomado, alt. 1,000 m, 6 August 1973, G.G. Musser rec. (AMNH 223467; ASE 378; Robert Traub coll. n B 94726).

Etymology: specific epithet derived from Rubrisciurus, the host genus.

Deposition of types: CMNH (Robert Traub Collection of Siphonaptera).

\section{DESCRIPTION}

This taxon is immediately characterized by the male, as belonging to the genus Medwayella, by the bristles preceding the stiva (here virtually absent) that totally mask its outline, and, secondarily, by the existence of only one acetabular bristle. The female does not show, a priori, distinguishing external characters, except, perhaps, for its very large size; the dimensions of the male are equally impressive, but this criterion is too uncertain to be a discriminating character.

Head (Fig. 5) with discontinuous setation. First frontal row situated some distance from the margin and composed of five bristles which increase in size from the dorsal region to the ventral region. The other rows are discontinuous, and collectively composed of a total of 10-12 large bristles; numerous micro-bristles are present in the supero-distal region. Eye incised ventrally, but not lobed. Occipital region with about 13 large bristles in three or four rows. Numerous micro-bristles are also present in the antero-superior region. The base of the antennal fossa is striated posteriorly, with fine elongate, diamond-shaped or sub-parallel lines.

Thorax. Prothorax with a ctenidium of 20-23 spines (males: 21 and 23; female: 20); this is sub-equal, or slightly less, than the dorsal length of the pronotum in males but clearly shorter in the female. Anterior to this ctenidium, there are several scattered small bristles and a row of seven long bristles. Mesothorax with 4-5 irregular rows of small bristles and a distal row of seven long bristles. One or two pseudo-setae present on each side, directly inserted under the collar. Metathorax: three rows of small bristles (the most anterior row is confined to the dorsal region) and a distal row having seven long bristles. Metepimeron: the spiracle is massive, slightly longer than wide, in the shape of an obtuse pine nut; it has 12 large bristles. Leg III with classic elongation of tarsal articles, as seen in fleas of squirrels.

Abdomen (unmodified segments): one spinule on each side on tergites II-IV in both sexes. There is a slight difference in setation between males and the single female. There are three rows of small bristles, the principal row starting on tergite II, and having eight large bristles in males, but with nine on tergite III, and ten on tergites IV-VI in the female. In males, the spiracle is situated between bristles 7 and 8; in the female, it is between bristles 8 and 9 on segment III, and between britsles 8 and 9 on segments IV-VI: there are therefore two bristles beneath the spiracles. These spiracles are conical, small, and decreasing in size from tergite II to tergite IV, then similar in size or slightly larger posteriorly.

Two large, robust ante-sensilial bristles on tergite VII; in the male, the longer is almost the same size as the "free" part of the telomere, the superior bristle is 3/5 as long as the the other bristle. In the female, the respective lengths of these two bristles can not be determined because they are broken. Characteristically, they are inserted between two small triangular lobes and accompanied by five robust bristles, that, at low magnification, appear to be a part of them. Male sternites: sternite II with one or two small bristles near the anterior margin and 4-6 marginals alligned on the ventral margin; sternite III with 8-12 bristles more or less in a group and one row of large bristles; sternite IV with 11 bristles and a row of four; sternite $\mathrm{V}$ with 9-11, and a row of four (or three); sternite VI with 8-11, and a row of 4-5; sternite VII with 10 or 11, and a row of 4-5. Female sternites: sternite II with an area of 19-20 small bristles near the anterior margin and six marginals of increasing size, the last curved inwards; sternite III with 14 bristles more or less in a group and a row of six large bristles; sternite IV with 16 bristles and a row of five or six; sternite $\mathrm{V}$ with 15 bristles and a row of six; sternite VI with 14 bristles and a row of six.

Abdomen (modified male segments): in segment VIII, the tergite is small, triangular and with the apex directed directed towards the base; sternite VIII (Fig. 6), characteristic of Medwayella with a "spinose" process on the ventral margin ("lumacaudate process" of Traub, 1972), this, nevertheless, appears to us to possess bristles, or a small thickening, rather than the more typical 
"spines"; the mesal bristles are clearly divided into two "bands", making the median part, smooth. Segment IX (Fig. 7): postero-ventral border of processus basimeris ventralis with one bristle and continuing directly with the corresponding margin of the manubrium. This area is wide. In the free part, the telomere (or processus telomeris) is slightly arched basally, then rectilinear. The robust para-apical bristles are highly pigmented and slightly arched. The most distal bristle totally masks the shape of the stiva. Sternite arm wide proximally, particularly in the superior 2/3; the distal arm is slender. The dorso-apical concavity is slightly rounded up to the subapical lobe. The setation of the ventral margin is a little aberrant in that the 4 or 5 superior "spines" are very small and short, not pigmented, and more rounded than pointed.

Phallosome (Fig. 8): median dorsal lobe (M.D.L. of Traub, 1972) of normal development for this genus and clearly angled; the alpha portion of Ford's sclerite is elongate along its dorso-apical border; the groove-like structure of this sclerite (GRV) is wide. Lower arm of securifer (L.A.), narrow and sinuous apically. Tubus interior long and relatively wide.

Abdomen (modified segments of female): sternite VII (Fig. 9) with 26 moderately sized bristles in a group, and one row of eight large bristles (four above the sinus, four below). Tergite VIII (Fig. 9) apparently without distinctive characters. Genital striations lateral to tergite VIII (M.R. 8, in Traub, 1972) difficult to visualize (Figs 9, 10); this region has thicker mounting medium and is difficult to decipher at high magnification; another difficultly is the presence of an artefact in this region. It seems to extend as a long and fine prolongation directed posteriorly.

Spermatheca and ducti (Fig. 10): except for the spermatheca, and for the same reasons as given for the lateral striations (one can add the over-clearing of the insect), the genital ducts are barely distinguishable: neither the "morion" ( $c f$. Traub, 1972), nor the dilated part of the ductus are visible. Figure 10 shows the anatomical position of these organs and of the striations. Of note ( $c f$. Fig. 9), are the small size of the spermatheca, and in particular of the billa, which is distinctly "pushed" into the bulga (but these characters are present, more or less universally, throughout the genus Medwayella) and the length/width ratio of the bulga which is close to $2 / 1$.

Dimensions (slide-mounted insects): holotype: 4,5 mm; allotype: 5,5 mm: paratype male: 4,4 $\mathrm{mm}$.

\section{Discussion}

We have already outlined in the introduction for the description of Medwayella rubrisciurae n. sp., the principal characters of the male. However, females belonging to this genus are so homogenous that Mardon (1981) did not provide a key to this sex, and we are obliged to admit our incapacity to bring to light a reliable character separating this female from other known Medwayella (the female of M. cambodia and some other species have been described since the publication of the key of Traub, 1972). Although the female described here is very large in size, this criterion is insufficiant for species determination. In our opinion, we must await the collection of a female in which the ducti and lateral genital striations of tergite VIII can be studied, in order to include this female in a dichotomous key. Although it is a weak criterion to which we do not adhere, it can however be stated that this is a large species of Medwayella that parasitizes Rubrisciurus rubriventer, a large, "red-bellied" tree squirrel that is endemic to Sulawesi.

\section{MACROSTYLOPHORA THERESAE N. SP.}

Specimens examined: holotype male ex Bunomys fratrorum (Thomas, 1896), (Rodentia, Muridae), Indonesia, Sulawesi Utara (North Sulawesi), Gunung Moajat, ca1780 m ( $\left.0^{\circ} 45^{\prime} \mathrm{N}, 124^{\circ} 25^{\prime} \mathrm{E}\right)$, August 1985, C.H.S. Watts rec. (Robert Traub collection $\mathrm{n}^{\circ} \mathrm{B}$ 98906. CW 121); Allotype female ex Paruromys dominator (Thomas, 1921), same data except: March 1985, L.A. Durden rec. (LAD \# 84); paratype male (partially dissected and damaged), same data as the holotype except: (Robert Traub collection $n^{\circ}$ B 98903. CW 118); paratype male ex Rattus xantburus (Gray, 1867), (Rodentia, Muridae), same data as the holotype except: (Robert Traub collection $\mathrm{n}^{\circ} \mathrm{B}$ 98905. CW 120). All specimens of $M$. theresae were collected during "Project Wallace" organized by the Royal Entomological Society (London) and the Indonesian Institute of Sciences (Lembaga Ilmu Pengehetuan Indonesia or LIPI).

Etymology: We dedicate this new species to Ms. Theresa Howard, Research Assistant in the Department of Entomology of the Natural History Museum [formerly, British Museum (Natural History)], London in recognition of her pleasantness and untirable energy in loaning the Siphonaptera specimens that we have requested from her over the years. This is a small testomonial of our recognition of her helpfulness.

Deposition of types: holotype, allotype and one paratype: CMNH (Robert Traub Collection of Siphonaptera); one paratype will be deposited in the Museum Zoologicum Bogoriense (MZB), Bogor, Indonesia.

\section{Description}

A non-stylophore species, belonging to the "euteles" group within the genus Macrostylophora Ewing, 1929 (Smit, 1983), or, according to Li \& Traub (1998) to the purely Oriental "euteles" group (the "bebeiensis" group is Palaearctic) of the sub-genus Shongshupsylla Li \& Traub of Macrostylophora. It is very close to M. euteles 

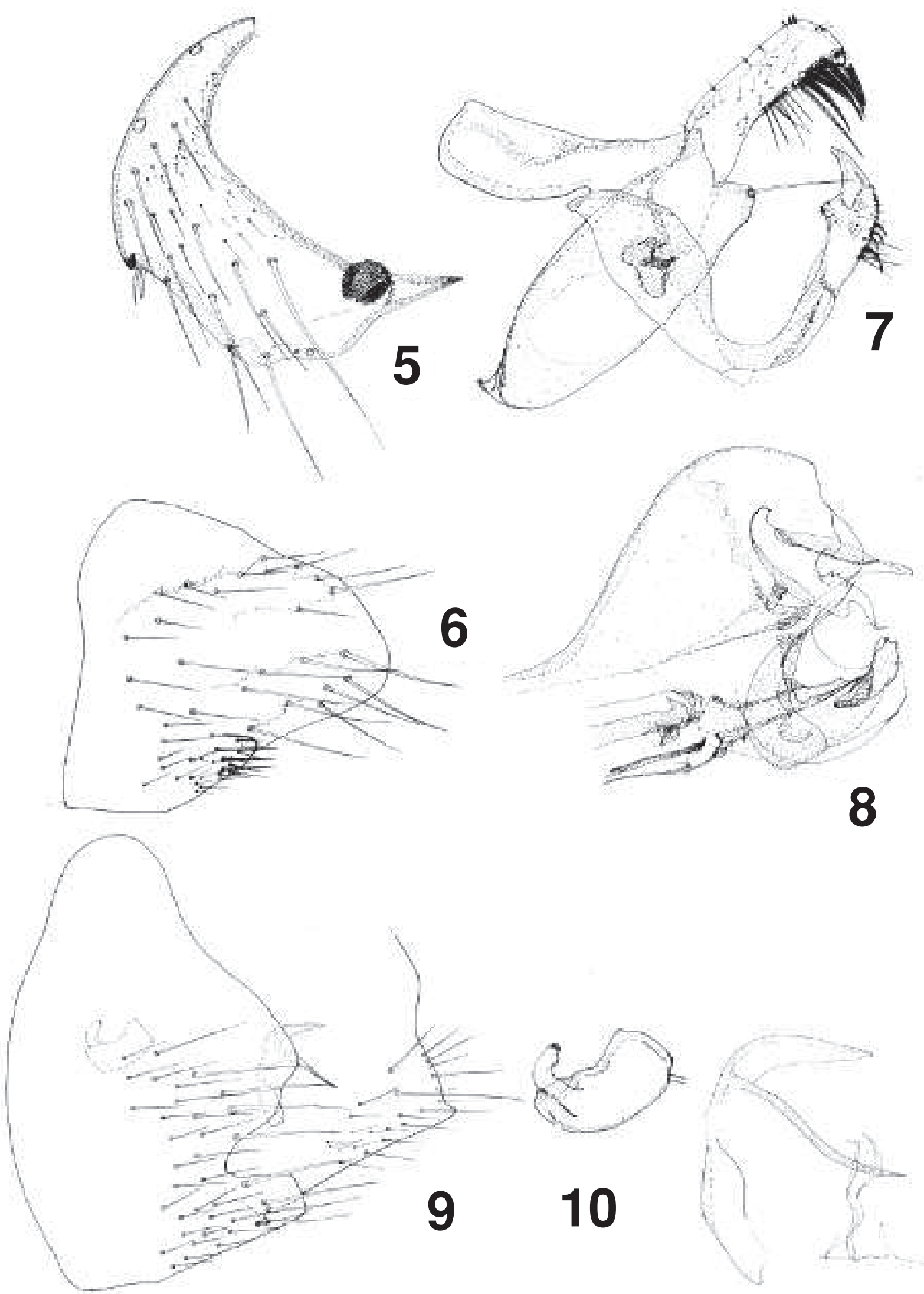

Figs 5-10. - Medwayella rubrosciurae n. sp. Holotype : Figs 5-8. Allotype: Figs 9, 10. - 5: frontal region of head; 6: sternite VIII; 7: abdominal segment IX; 8: apex of phallosome; 9: tergite VIII (partim) and sternite VII; 10: spermatheca, ductus (pro parte) and striated genitalia. 
(Jordan \& Rothschild, 1911) and M. cuii Liu, Wu \& $\mathrm{Yu}, 1964$. Note, in this paper, that the emended name of $M$. cuiae (used in Fauna Sinica, 1986 and by Traub et al., 1983) is not perfectly justified to us, unless the collector, "Comrade S.T. Cui", was a woman. Similarly (in Fauna sinica, 1986), we do not consider the placement of $M$. jiangkouensis Li \& Huang, 1979, as a sub-species of $M$. cuii to be valid; it is, in our opinions, as also noted by Li \& Traub (1998), a "good species".

Head: fracticipit in the male, integricipit in the female. Rounded anteriorly ; frontal tubercule very small. Three rows of bristles in the frontal region: the $1^{\text {st }}$ composed of one small bristle, the $2^{\text {nd }}$ having three medium bristles, the $3^{\text {rd }}$ (or preocular) having three large bristles. Occipital setation in three "rows", the $1^{\text {st }}$ with one bristle, the $2^{\text {nd }}$ with one or two (the superior being small), and the $3^{\text {rd }}$ with four or five bristles, of increasing size from dorsal to to ventral. Labial palp composed of five articles, the last extending halfway along the length of the trochanter.

Thorax. Prothorax with a ctenidium of 17 or 18 spines in males, 16 in the female; one anterior row of six bristles. Mesothorax: four rows of bristles, with respectively, two, five, six and seven bristles; one pseudoseta beneath the collar. Metathorax: three rows of bristles with, respectively, five, 12 and 7 bristles, the last ones being long. The metepimeron has six bristles of which none are particularly large; spiracle rounded, little developed. Legs typical for this genus.

Abdomen (unmodified segments): tergite I with one spinule; two or three spinules on tergite II, one on tergite III, zero or one on tergite IV, and zero on the following tergites. Seven large bristles in the principal row on the tergites: in the males, the last row is close to the spiracle, which is always rounded; in the female, this is situated between bristles 6 and 7. Tergite VII of males has one large bristle flanked by two minuscule ones; in the female, there are three bristles in the ratio (from dorsal to ventral), 1-5-4. Sternites: sternite II in both sexes devoid of bristles; in males, sternites III-V have two bristles, sternites VI and VII have three bristles. In the female, sternite III has two bristles, sternites IV-VI have three or four bristles, and sternite VII (cf. Fig. 14) has four or five bristles. We noted the presence of hypopes of Acaridae (resembling Psylloglyphus), beneath sternite IV of the female.

Abdomen (modified male segments). Wagner's gland is absent. Segment VIII: tergite (Fig. 11), subcircular, with 11 or 12 large bristles, and some small ones, marginal or submarginal, all inserted on the superior quarter of the segment; lacking a spiculose zone; sternite VIII (Fig. 12) narrow with one bristle and terminating in a long and complex vexillum, clearly bifid. It is clearly connected to sternite IX by an intersegmentary lobe that is covered with micro-spicules. Segment IX
(Fig. 12): tergite wide at apodeme and comparatively narrow at manubrium, arched towards the base, and with a triangular lobe in the superior third of its dorsal border. Dorsal lobe of processus basimeris, long, fine, and discretely curved apically; two acetabular bristles. Processus telomeris more or less triangular, its posterior (or dorso-apical) margin practically rectilinear, with two bristles of which the superior is the longer, curved or sinuous, depending on the specimen; the two drawings of which we are aware for $M$. euteles (that of Jordan \& Rothschild (1911) and that in "Fauna Sinica"), differ with respect to these organs. At its inferior angle (internal surface), there are four thick bristles, pigmented, finely striated, and undulating. Sternite: proximal arm lacking specific characters; distal arm with a wide apex and more or less rounded, covered in micro-bristles (characteristic of the genus Macrostylophora) and having a beaked retrograde lobe, with an essentially equally large bristle, pigmented, widening on the slide, then unravelling into a point. In the postero-ventral part of this widening zone, we note a long, colorless, slightly curved extension that is directed towards the base; its equivalent on the other side is easily visible and eliminates a priori any probability of an artifact. We have not discerned an analagous organ in any other Macrostylophora examined, except in $M$. euteles, but the nature of its origin is unclear to us.

Phallosome (Fig. 13): the hamulus appears to us to be the most original character of the species examined, and, despite an artifact due to too much clearing, it seems to be small in size and of a different shape than that of other apparent species. Also, in comparing the drawing of the phallosome of $M$. "cuiae" given by Liu et al. (1964), the ductus (armature of sclerotized inner tube of aedeagus or "a.i.t." in Rothschild \& Traub, 1971; labeled in error as "b.i.t." in Liu et al., 1964), is straight, relatively long and not curved towards the base.

Abdomen (modified female segments) (Fig. 14): sternite VII not crescent-shaped basally, and having four large bristles. Tergite VIII clearly crescent-shaped in the infero-distal region. Anal stylet with parallel borders $(\mathrm{L} / 1=\sim 3,5)$; in $M$. euteles, it is conical and shorter; in M. cuii, this organ is as long as in our species but the apex is clearly withdrawn. Sternite VIII not distinctive. Spermatheca and ducti (Fig. 15): bulga cylindrical, billa curved, a little shorter than the bulga; ductus communis slightly sinuous, with parallel borders; ductus spermathecae thick and relatively short ; ductus obturatus shorter than the bulga. In M. euteles, the spermatheca is practically identical to this; in M. cuii, the bulga has convex borders and the billa is thicker and more curved.

Dimensions (slide-mounted insects): holotype: $2,3 \mathrm{~mm}$; allotype: 2,7 mm; paratypes males: 2,2 and 2, $5 \mathrm{~mm}$. 


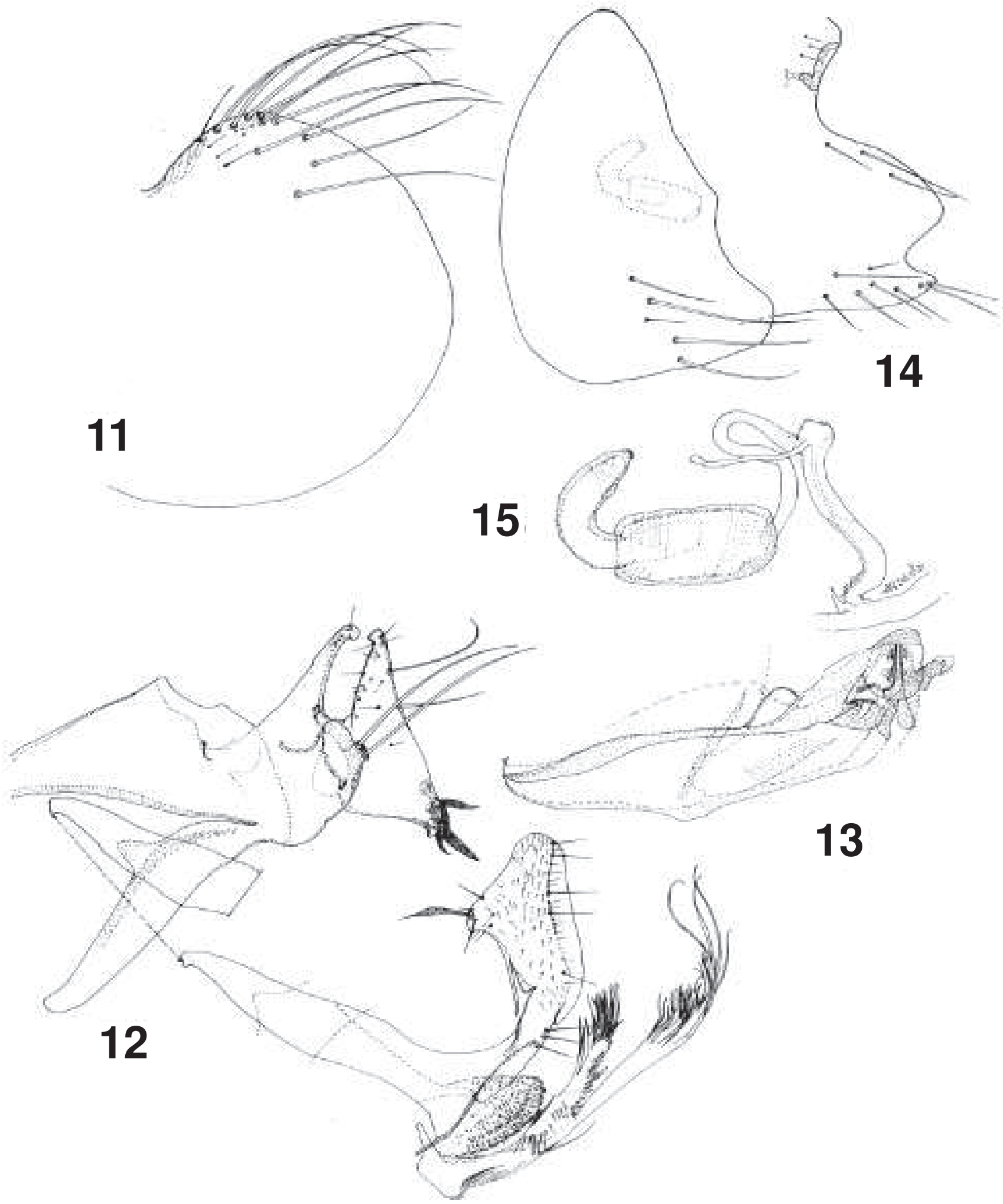

Figs 11-15. - Macrostylophora theresae. Holotype: Figs 11-13. Allotype: Figs 14,15. - 11: tergite VIII; 12: sternite VIII and abdominal segment IX; 13: phallosome; 14: sternite VII and tergite VIII (partim); 15: spermatheca and ducti. 


\section{DISCUSSION}

W

e had intended to name this taxon "cephaloeafaciens" from "cephaloea", a term used by Pliny the Elder for designating the original use of this Greek word, meaning head, or cephalic region, and of "faciens", a Latin term signifying in this case "to give, to procure". However, because of the ease with which this systematic problem could be resolved after the receipt of voucher specimens loaned from the Department of Entomology of the Natural History Museum in London, the amenity, consideration and help furnished by Ms. Theresa Howard was decisive!

The "euteles" group is, for the most part, very homogeneous. After in depth study, we found two taxa to be similar as previously discussed, although a number of other species show remarkably similar morphology, for exemple, M. bispiniformis, M. hebeiensis, M. jiangkouensis...

Our comparison was limited to M. euteles (Jordan \& Rothschild, 1911) and M. cuii Liu, Wu \& Yu, 1964. We have, here and in the descriptive text, given some points of discordance or of convergence within these two taxa. We will proceed here, to briefly provide or repeat the discriminating characters.

In the male genital segments, the dorsal lobe of the processus basimeris is much shorter in $M$. euteles, but slightly different in $M$. cuii; the processus acetabularis is, comparatively, more bulky in euteles, but the difference is minimal in comparison in cuii (ventral part more angular?). The processus telomeris has an apex that is clearly wider in euteles and discretely wider in cuii; the ventral border is very sinuous in euteles, a little more than in Macrostylophora theresae and cuii; in these two species, the postero-ventral apex is an acuminate crochet; similarly, there are four large spiniform bristles in $M$. theresae, and three present in the same region in euteles and cuii, because one of them is not spiniform. The apex of sternite IX is very close in euteles (but the thick bristles are very different) but it is nearly quadrangular in cuii. In the female that we have seen, the anal stylet is different in euteles, but very close in cuii ; further, the spermatheca of $M$. theresae is not distinguishable from that of euteles, but differs from that of cuii.

Macrostylophora euteles is known from southern China and from Thailand (Traub et al., 1983) and M. cuii only from southern China. Traub et al. (1983) noted that the genus Macrostylophora is known from "...the Oriental Region and into the periphery of the Palaearctic and Wallacean,... although the genus has not yet been reported in Sulawesi”. Durden \& Traub (1990) updated and corrected this last point in noting the presence of Macrostylophora on this island, a taxon that that they stated might be a subspecies of a species known by other subspecies from China, Taiwan and Borneo. This taxon is M. theresae, a species whose morphology has evidently created some confusion with other species and subspecies of Macrostylophora.

Although we only report four specimens of $M$. theresae, all from North Sulawesi (and a $5^{\text {th }}$ specimen that is probably $M$. theresae from Central Sulawesi - see below), it is interesting to note that all of these specimens were collected from endemic murine rodents. The remaining 30 species of Macrostylophora (this includes some, as yet, undescribed species) are ectoparasites of squirrels, especially members of the tribe Callosciurini in the Oriental and southern Palaearctic regions (Traub et al., 1983). This suggests that either $M$. theresae has switched to parasitizing a different group of hosts (murine murids) on Sulawesi, or that its true hosts are callosciurine squirrels with a few specimens being stragglers (= vagabonds) on murids. Three genera and six species of indigenous callosciurines are currently recognized as occuring on Sulawesi and all of these taxa are endemic (Musser, 1987; Corbet \& Hill, 1992). On Gunung (mount) Moajat, where the four type specimens of $M$. theresae were collected, one of us (LAD) saw the endemic callosciurines Rubrisciurus rubriventer and Prosciurillus murinus (Müller \& Schlegel, 1844). However, no callosciurines could be livetrapped at this site and only one fresh specimen of $R$. rubriventer that had been killed by a local poacher was examined; unfortunately, no fleas were found on this squirrel. Two species in the pygiopsyllid genus Farhangia are known to parasitize Prosciurillus spp. squirrels in Sulawesi (Traub, 1980, Mardon \& Durden, 2003) so, if the true host of $M$. theresae is a callosciurine, we suggest that this host could be $R$. rubriventer which is widespread and relatively common throughout Sulawesi (Musser, 1987). Although it was not seen on Gunung Moajat, the Sulawesi lowland longnosed ground squirrel, Hyosciurus ileile Tate \& Archbold, 1936, has also been recorded in North Sulawesi (Corbet \& Hill, 1992). However, this squirrel appears to be confined to elevations below and up to $1,500 \mathrm{~m}$ and our collections of $M$. theresae were made at elevations of at least $1,780 \mathrm{~m}$. Therefore, the puzzle regarding the true host associations of $M$. theresae remains unsolved.

Lastly, we note, the presence in our material of another female example of Macrostylophora; although it is very close morphologically, we prefer not to include it in the type material. Its collection data are as follows: ex Bunomys penitus (Miller \& Hollister, 1921) (Rodentia: Muridae) (AMNH 225310; ASE 2556; Robert Traub collection $n^{\circ}$ B 94826)/Indonesia: Central Sulawesi, Gunung Nokilalaki (1' $16^{\prime} \mathrm{S}, 120^{\circ} 10^{\prime} \mathrm{E}$,), 6,000 ft. (1,829 m) G.G. Musser rec.; 24 Feb. 1975. 


\section{ACKNOWLEDGEMENTS}

W e are grateful to John Rawlins (Carnegie Museum of Natural History, Pittsburgh, USA) and Theresa Howard (Natural History Museum, London) for loaning flea specimens for description and comparison. We thank Guy G. Musser (American Museum of Natural History/AMNH, New York), Christopher H.S. Watts (University of South Australia, Adelaide) and Sampurno Kadarsan (Indonesian Insititute of Sciences) for collecting some of the flea specimens discussed in this paper. We also thank Guy Musser for providing collection data and other information on Sulawesi rodents. Other persons who helped with aspects of this study are Jeremy D. Holloway (fomerly, C.A.B. Institute of Entomology, London) and the late Robert Traub (formerly, U.S. National Museum, Smithsonian Institution, Washington DC). The Indonesian Institute of Sciences (Lembaga Ilmu Pegehutuan Indonesia) (LIPI) and Dante Sembel (Sam Ratulangi University, Manado, Indonesia) facilitated field collections in Sulawesi. L.A. Durden's fieldwork in Sulawesi was conducted as part of "Project Wallace" organized by the Royal Entomological Society (London) and LIPI, and funded by the Committee for Research and Exploration of the National Geographic Society (Washington DC). L.A. Durden's research at the AMNH was funded in part by the Celebes Fund. This paper is "Results of Project Wallace number 159".

\section{REFERENCES}

Beaucournu J.C. \& Durden L.A. Neopsylla musseri n. sp. (Siphonaptera - Ctenophthalmidae) puce nouvelle du Sulawesi Central (Indonésie). Parasite, 1999, 6, 163-167.

Beaucournu J.C. \& Durden L.A. Deux Stivalius (SiphonapteraPygiopsyllidae-Pygiopsyllinae) nouveaux d'Indonésie. Parasite, 2001, 8, 147-153.

Beaucournu J.C. \& Gallardo M.H. Quelques nouvelles puces du Chili (Siphonaptera) parasites de Ctenomys (Rod., Octodontidae). Bulletin de la Société de Pathologie exotique, 1977, 70, 438-450.

Corbet G.B. \& Hill J.E. The mammals of the IndoMalayan region: a systematic review. Oxford University Press, 1992.

Durden L.A. \& Beaucournu J.C. The flea genus Sigmactenus: three new taxa from Sulawesi, identification key, and distribution map for all known species and subspecies. Parasite, 2000, 7, 151-165.

Durden L.A. \& BeAucournu J.C. Gymnomoeropsylla n. gen. (Siphonaptera: Pygiopsyllidae) from Sulawesi, Indonesia, with the description of two new species. Parasite, 2002, 9, 225-232.

Durden L. \& Traub R. Zoogeographical implications from rodent ectoparasites in Sulawesi, in: Insects and the rain forests of South East Asia (Wallacea), Knight W.J. \& Hol- loway J.D. (eds.), The Royal entomological Society, London, 1990, 57-62.

JORDAN K. Siphonaptera collected by Harold Stevens on the Kelley-Roosevelt expedition in Yunnan and Szechuan. Novitates Zoologicae, 1932, 38, 276-290.

LEwIS R.E. \& Jones G.S. Some Fleas (Siphonaptera) from Sulawesi Selatan, with the description of three new species. Journal of Medical Entomology, 1985, 22, 204-211.

Li K.C. \& Traub R. Description of Songshupsylla, a new subgenus of Macrostylophora (Siphonaptera: Ceratophyllidae), with a discussion of its species groups. Journal of Medical Entomology, 1998, 35, 396-398.

Liu C.Y., Wu H.Y. \& Yu J.F. [On a new species of the genus Macrostylophora (Siphonaptera: Ceratophyllidae)]. Acta Zootaxonomica Sinica, 1964, 1, 163-166 (in Chinese, English abstract).

Liu Z. et al. Fauna sinica, Insecta, Siphonaptera. Sciences Press, Beijing, 1986, XXIII (in Chinese, English summary).

MARDON D.K. On the relationships, classification, aedeagal morphology and zoogeography of the genera of Pygiopsyllidae (Insecta: Siphonaptera). Australian Journal of Zoology, Supplementary Series, 1978, 64, 1-69.

MARDON D.K. An illustrated Catalogue of the Rothschild collection of Fleas (Siphonaptera) in the British Museum (Natural History), Volume VI: Pygiopsyllidae. British Museum (Natural History), London, 1981, 298 p.

Mardon D.K. \& Durden L.A. New species of the fleas Farhangia and Nestivalius (Siphonaptera: Pygiopsyllidae) from endemic rodents in Sulawesi, Indonesia. Medical and Veterinary Entomology 2003, 17, 75-86.

Musser G.G. Definition and contents of the Sundaic genus Maxomys (Rodentia, Muridae). Journal of Mammalogy 1979, 60, 592-606.

Musser G.G. The mammals of Sulawesi, in: Biogeographical evolution of the Malay archipelago, Whitmore T.C. (ed.), Oxford, Clarendon Press, 1987, 73-93.

Smit F.G.A.M. On some adaptative structures in Siphonaptera. Folia Parasitologica, Praha, 1972, 19, 5-17.

SMIT F.G.A.M. Key to the genera and subgenera of Ceratophyllidae, 1-36 + 205 figures, in: Traub R., Rothschild M. \& Haddow J.F., The Rothschild Collection of Fleas. The Ceratophyllidae: Key to the Genera and Host relationships. Privately printed by Miriam Rothschild \& Robert Traub, Cambridge, 1983.

SмIT F.G.A.M. List of genera and subgenera of Siphonaptera (2-7), in: An illustrated Catalogue of the Rothschild Collection of Fleas. Volume VII, Malacopsylloidea (Malacopsyllidae and Rhopalopsyllidae), Oxford \& London, 1987.

Rothschild M. \& Traub R. Glossary to Volume V (p. 8-85) in: Hopkins G.H.E. \& Rothschild M., An illustrated Catalogue of the Rothschild Collection of Fleas (Siphonaptera) in the British Museum (Natural History). Volume V: Leptopsyllidae and Ancistropsyllidae. London, 1971, 530.

Traub R. Malaysian parasites - XVII. Four new species of Fleas (Siphonaptera). Malaya, Institute for Medical Research, 1957, 28, 35-64. 
Traub R. The Gunong Benom expedition, 1967. 11. Notes on zoogeography, convergent evolution and taxonomy of fleas (Siphonaptera), based on collections from Gunong Benom and elsewhere in south-east Asia. I. New taxa (Pygiopsyllidae, Pygiopsyllinae). Bulletin of the British Museum (Natural History), Zoology, London, 1972, 23, 203305.

Traub R. New genera and subgenera of pygiopsyllid fleas, in: Proceedings of the International Conference of Fleas - Ashton Wold/Peterborough/UK/21-25 June 1977, Traub R. \& Starke H. (eds.), A.A. Balkema, Rotterdam, 1980, 13-29.

Traub R., Rothschild M. \& Haddow J.F. The Rothschild collection of Fleas. The Ceratophyllidae: key to the genera and host relationships. Privately printed by Miriam Rothschild \& Robert Traub, Cambridge, 1983.

Reçu le 5 mai 2006 Accepté le 15 juin 2006 